\title{
Colloquy
}

\section{CARE AND THE NONHUMAN POLITICS OF VETERAN DRUNK DRIVING}

\author{
KEN MACLEISH \\ Vanderbilt University \\ (D) http:/ / orcid.org/0000-0003-4815-9291
}

There was a story circulating on the internet in the fall of 2015, in the certainty-inspiring form of a police blotter announcement, that tells of a Navy Petty Officer First Class whose drinking and driving had left him saddled with a breathalyzer ignition lock in his car. At the end of a subsequent night of drinking, this seaman knew that his intoxication would prevent him from starting his car, so he procured a raccoon rummaging in a trash can in a nearby park, brought it to the car, inserted the interlock tube into its mouth, and squeezed an exhalation from it that satisfied the interlock's chemical sentry. The raccoon collapsed unconscious on the floor of the car, the story goes, and then awoke to attack its abductor as the latter drove triumphantly away. The distracted seaman crashed his car through a fence and into a swimming pool, where police later found him covered in bites and scratches. He was charged with drunk driving and "abuse of a public animal."

The story is the fictional product of a military humor website, ${ }^{1}$ but a number of regional, national, and military news outlets initially reported it as true, and the tale made the social media rounds as well. Its absurdity seems to have lent it credibility as it went speeding and crashing around the internet, fueled by the hilarity of the badly behaved service member — a literal drunken sailor. 
The story's ready believability arguably serves as a sign of its underlying cultural truth. Its cyborgian, human-animal-machine assemblage hurtling dangerously across the landscape, violently divided within itself and a threat to the home-front world around it, affirms a deeply engrained American tendency to regard the same veterans who are the avatars of foreign policy violently inflicted on the rest of the world as problematic threats to domestic social order, which also then makes them candidates for controlling forms of care. Configurations of the "problem veteran" (Kinder 2015) as a morally hazardous dependent of the state, a failed agent of economic and sexual reproduction, or a criminal deviant underlie many past and present discourses of civilian support. That is to say, both historically and in the present, the hegemonic modes of caring for and caring about veterans are inextricably bound up not only with the heroic violence of foreign battlefields but also with domestic hierarchies of race, gender, sexuality, disability, capital, and nation (Millar 2015; Wool 2015). At the same time, the spectacular and pitiable aftermaths, excesses, and residues of war attributed to military subjects frequently serve to distance and distinguish violence wrought on foreign populations from domestic terrains and actors characterized by order, right, and peace (Favret 2010; Howell 2018; Kaplan 2018). If attended to care-fully, the story and the denigrated form of life at its center can trace war's use of force and vital instrumentalism from its remote overseas deployments to the heart of the domestic orders it is meant to defend.

I was prepared to believe the raccoon story myself because of my own ethnographic immersion in care practices aimed at ostensibly "disorderly" military and veteran populations. I read the story while in the midst of three years of fieldwork in a veteran treatment court (VTC) in a military town in the U.S. south - "Hullford" - with a large population of post-9/11 veterans. The first VTCs were started in 2008, modeled on other nonadversarial helping courts that focus on offenders with mental health or substance use problems. There are now more than three hundred veteran-specific programs around the country in civilian municipal and county courts (Lithwick 2010; Justice for Vets n.d.). These treatment courts offer twelve to eighteen months of supervised rehabilitation in place of jail time for military and veteran offenders charged with DUI, drug possession, assault, and other non-felony crimes. Court participants are subject to regular drug and alcohol testing, evening curfews, and the threat of incarceration if they violate program rules. The court also helps connect them with a host of medical and financial veteran benefits that many have yet to access. The sixty or so veterans and active-duty soldiers that the Hullford court can accommodate at any given time tend 
to skew young and male, many having deployed as part of the U.S. wars in Iraq and Afghanistan.

Veteran treatment courts are explicitly premised on a tight causal linkage between military service, mental illness, and lawbreaking. In this real-world enmeshment of military life in constraining and coercive care, the non-human adjuncts of the animal and the automobile - the raccoon and the car in the apocryphal sailor's story — can help illuminate how the disorderly subjects of veteran care are figured.

First, the animal: the story traffics in an otherness signaled not only by the apocryphal sailor's lawbreaking, dissolution, and abject haplessness but also by his intimate cross-species deception, mimicry, and "abuse." Animality locates soldiers' and veterans' status as problematic, disorderly, or ungovernable home-front presences amid the other populations and figures of attenuated humanity produced by globalized war-making (cf. Pandian 2008; Kosek 2010). References to and uses of animals in war-totemic eagles or wolves, say, or the virtuosic nose, ears, and teeth of trained military working dogs like the ones who famously cornered high-profile terrorists such as Osama bin Laden or Abu Bakr al-Baghdadi-point to the limits of humans' physical and technological capacities. Animality haunts breakdowns of human self-mastery in the face of war's terror, trauma, pain, cruelty, and exhaustion, revealing limits to what the biopolitical control of military life can actually do. As Ryan Hediger (2013) writes, when life escapes from those mechanisms that fantasize its perfect realization, instrumentalization, and control as human - especially when it does so in notably clumsy or abject ways - it can look like, even be, an animal.

In the world of the veteran court, the symptoms of the posttraumatic stress presumed to lead soldiers to lawbreaking are characterized by experts and laypeople alike as the excessive activation of the evolutionarily obsolescent fight-or-flight threat response - the animal lurking within and suddenly possessing the human. The judge, the case managers, and the participants themselves pepper the court's semiscripted speech with invocations of unruly brains or bodies that "aren't used to" life at home or that "think they're under attack" in the face of benign but triggering stimuli. Alcohol, as well as the marijuana, opioids, and methamphetamines that together account for the majority of the cases that show up in the court, tends to be extremely effective - up to a point, and not without cost — for managing the depression, anxiety, hypervigilance, anhedonia, social withdrawal, sleep disturbance, and aggression associated with post-traumatic stress disorder (PTSD). But even as alcohol and other drugs help blunt the unwanted animal becomings of war trauma, they constitute their own threat, what the national veteran court 
advocacy and credentialing organization Justice for Vets calls a "cycle" of mental distress, substance use, crime, arrest, lack of treatment, and re-arrest in which veterans traumatized by war may be trapped. Breaking that cycle then becomes a project of agentive, responsibilized re-humanization with which court participants are invited to identify.

As in the story of the sailor, the animal does not operate in a vacuum here, but as part of a kind of jalopy-like cyborgian assemblage that also entails a logic of automobility. More than three-quarters of the Hullford VTC participants are there for DUIs or other alcohol-related charges. Both heavy drinking and reckless driving are deeply engrained in Army culture, especially among junior enlisted soldiers, and Hullford and its semirural surroundings are, like most military communities, car-centric landscapes. This confluence of factors makes drunk driving an inevitability and a ready target for the policing of soldiers and veterans, and it also almost renders invisible the sympathetic animality of PTSD symptomatology when DUI is treated foremost as an administrative or criminal offense and only later, under the court's caring eye, as a sign of trauma. Many of my acquaintances in the VTC interpret this state of affairs as veterans being set up to fail by both an uncaring military that discourages asking for help and is eager to trim the ranks of troublesome soldiers and a predatory civilian world that sees veterans either as a threat or a source of revenue. ${ }^{2}$ Susan, an Army vet and contractor who did deployments in Iraq and Afghanistan as an intelligence analyst, said of the Hullford cops, "They know we're out here. They know where the bars are. . . Cops know that vets are gonna drink and shouldn't drive, but instead of helping 'em, they put 'em in jail!" She had been through VTC for her own DUI, and on the day of this particular conversation she had just come from visiting an active-duty friend she was hoping to help get into the program: he had done five tours, she told me, and really needed help with his PTSD, but now the Army was trying to kick him out over a DUI. "Back in the day," Susan told me, "you could get two, three, four DUIs and they would handle it internally, support you, keep you from getting in too much trouble, see if you needed help. Now we get this crap-guys are in trouble and they just wanna get rid of them."

Here too, behind the wheel, the problem vet appears as both more and less than human to civilians and supervising institutions: machinic, tool-like, and mindlessly subordinate, but also technologically enhanced, hypercapable, and prone to running out of control. For Felix, a Vietnam veteran who was one of the first program graduates (he was on his third DUI arrest) and who now volunteers as a court mentor for younger vets, this dynamic is nothing less than trauma man- 
ifesting in plain sight as disorderly kinesis. "If you don't get injured," he said of young soldiers, "you come back with this invincible feeling. You see it in this town, all these Mustangs and crotch rockets" - the muscle cars and sport bikes that peel away from stoplights and can be heard roaring and whining their way down Hullford's highways at high rev. "All these guys are pumped up," their aggression echoing the automotive violence seen, endured, and perpetrated by soldiers in the counterinsurgency terrain of Afghanistan and Iraq: ambushes, vehicle-borne bombs, pedestrian injuries and deaths, checkpoint and convoy security carried out with machine guns and unforgiving rules of engagement.

As venues of dangerously failed self-management, the road and the car furnish the court with its opportunities to do caring work: drunk driving, speeding, reckless driving, the drugs and paraphernalia secreted in a glove box or under a seat, and confrontations or assaults stemming from road rage are all where individual pathology becomes a crime and a threat, still strangely valorized by association with war but also available for reform and healing. Court participants themselves, in the short, confessional speeches they give on advancing from one to the next phase of the program, thank the officers or deputies who pulled them over and cast roadside arrest as a moment of transformative intervention. More than one narrates these enforcements as literally lifesaving, describing police stops that likely prevented fatal traffic accidents or that interrupted journeys that would have otherwise ended with premeditated violence or self-inflicted harm.

Messier here is the way that automobility is also a space within which veterans' lives may fall further apart, whether despite or because of the surveillance and solicitous, caring attention that binds them. The court does not use interlock breathalyzers, preferring instead handheld alcohol monitors that can be mined for GPS data and make it possible to catch participants violating curfew or visiting bars or liquor stores. Many DUI arrests lead to suspended licenses, depriving participants of the both symbolic and practical necessity of automotive sovereignty and leaving them to navigate work, home, court, medical care, and school with buses, bikes, and the kindness of friends and kin. Continuing to drive on a suspended license makes for a major temptation that sets participants up for aggressive sanction from the court, as well as the possibility of new criminal charges. Those still legally allowed on the road may also be immobilized by the expense of loan payments, repairs, gas, and exploitative fees and lending through which automobility propagates inequality (Lutz 2014). While for Felix, veteran bodies behind the wheel trace the violence of foreign battlefields and inscribe it anew on home-front terrain, the domestic highway constitutes its own largely unquestioned 
system of mass death and vulnerability. The animal-abusing sailor might stand out as an exception, but he points to the rule that driving is a horrifically dangerous activity: a politically normalized accident (Beckmann 2004; Virilio 2006) that blurs the lines between victim and threat. As with war, automobility unequally distributes harm along racial and geographical lines and bears a hefty body count alternately hidden from view and sensationalized as grist for moral panic.

Read in one direction, the sailor, raccoon, and breathalyzer promise that the harms and excesses of war can be kept at a safe distance; like so many scratches and bites, the need for care and the limits to what it might accomplish announce themselves as traces on dangerous and ungovernable bodies. To be marked by one system of violence means to be normalized into another, whether by one's own dangerous improvisations, the coercion of a caring authority, or perhaps by some combination. Diana, another participant, was the only person I knew who had a breathalyzer interlock. She had received it from the DUI court she was in before entering the VTC and paid out of pocket to keep it in her car. It came after her last charge. Diana had been drinking at home, avoiding the triggering sound of the 4th-of-July fireworks, and packing for a field exercise. A friend stranded at a bar called to ask for a ride. Another driver, also drunk, smashed into Diana's tiny sportscar head on at forty miles an hour. She was hospitalized with a traumatic brain injury. When I visited her, her apartment living room was dominated by a new, primer-black fender for the car and a carpeted hutch with two cats drowsily nesting in it. "I love this thing," she told me of the interlock. "I'm so glad it's there. I don't want to kill anybody."

\begin{abstract}
Military veteran drunk driving is a field of pathologized behavior in which traces of military excess meet the surveillance and banality of home-front safety. In communities with significant veteran populations, drunk driving blurs the lines between battlefield dangers and more familiar modes of domestic disorderliness, and the deployment of special mechanisms for dealing with law-breaking veterans gives rise to novel combinations of dangerous and deserving, criminal and cared-for. This article recognizes and questions the production of knowledge that is as ambivalent as the scenes of life from which it emerges. [care; military mental health; nonhuman politics]
\end{abstract}

\title{
NOTES
}

Acknowledgments This research was made possible by a Wenner-Gren Foundation PostPhD Fieldwork Grant and a Vanderbilt University Research Scholar Faculty Development Grant. Special thanks to Susan, Felix, and my numerous other interlocutors whom I cannot thank by name for their time, trust, and insights. Thanks to Sarah Besky, Jenny Carlson, 
Ashley Drake, Aimi Hamraie, Ali Howell, O. A. Lindsey, Cathy Lutz, Alex Nading, Rachael Pomerantz, Nisha Shah, Laura Stark, Debbie Weinstein, Zoë Wool, and audiences at the 2017 meeting of the Society for the Social Studies of Science, the 2018 meeting of the International Studies Association, and a presentation audience at the Watson Institute for International and Public Affairs for the discussion of and comments on various versions of this article. Special thanks to Lauren Cubellis and my fellow participants at the 2018 Wenner-Gren Foundation Workshop on theoretical and ethnographic approaches to care at Washington University in St. Louis.

1. The site, Just the Tip of the Spear (jttos.com), was subsequently shut down in 2016 for its role in supporting the massive military photo-sharing and revenge-porn ring known as Marines United (Keller 2017).

2. Since 2012, the Army has been aggressively downsizing, specifically singling out "risky" personnel with mental health and substance use issues for "deselection" (U.S. Army 2012).

\section{REFERENCES}

Beckmann, Jörg

2004 “Mobility and Safety." Theory, Culture and Society 21, nos. 4-5: 81-100. https://doi. org $/ 10.1177 \% 2 \mathrm{~F} 0263276404046062$.

Favret, Mary A.

2010 War at a Distance: Romanticism and the Making of Modern Wartime. Princeton, N.J.: Princeton University Press.

Hediger, Ryan

2013 Animals and War: Studies of Europe and North America. Boston: Brill.

Howell, Alison

2018 'Forget 'Militarization': Race, Disability and the 'Martial Politics' of the Police and of the University." International Feminist Journal of Politics 20, no. 2: 117-36. https://doi.org/10.1080/14616742.2018.1447310.

Justice for Vets

n.d. "What Is a Veterans Treatment Court?” Justice for Vets. Accessed August 20, 2019. http://www.justiceforvets.org/what-is-a-veterans-treatment-court.

Kaplan, Caren

2018 Aerial Aftermaths: Wartime from Above. Durham, N.C.: Duke University Press.

Keller, Jared

2017 "The Rise and Fall (and Rise) of 'Marines United." Task and Purpose, March 16.

Kinder, John M. https://taskandpurpose.com/rise-fall-rise-marines-united.

2015 Paying with Their Bodies: American War and the Problem of the Disabled Veteran. Chicago: University of Chicago Press.

Kosek, Jake

2010 "Ecologies of Empire: On the New Uses of the Honeybee." Cultural Anthropology 25, no. 4: 650-78. https://doi.org/10.1111/j.1548-1360.2010.01073.x.

Lithwick, Dahlia

2010 "A Separate Peace: Specialized Courts for War Veterans Work Wonders. But Why Stop at Veterans?" Slate, February 11. https://slate.com/news-andpolitics/2010/02/specialized-courts-for-war-veterans-work-wonders-but-why-

Lutz, Catherine stop-at-veterans.html.

2014 “The U.S. Car Colossus and the Production of Inequality." American Ethnologist 41, no. 2: 232-45. https://doi.org/10.1111/amet.12072. 
Millar, Katharine M.

2015 “'They need our help': Non-governmental Organizations and the Subjectifying Dynamics of the Military as Social Cause." Media, War and Conflict 9, no. 1: 9-26.

Pandian, Anand https://doi.org/10.1177\%2F1750635215606867.

2008 "Pastoral Power in the Postcolony: On the Biopolitics of the Criminal Animal in South India." Cultural Anthropology 23, no. 1: 85-117. https://doi.org/10.1111/ j.1548-1360.2008.00004.x.

U.S. Army

2012 "Army 2020: Generating Health and Discipline in the Force Ahead of the Strategic Virilio, Paul Reset." Washington, D.C.: Department of the Army.

2006 Speed and Politics. Los Angeles: Semiotext(e). Originally published in 1977.

Wool, Zoë H.

2015 After War: The Weight of Life at Walter Reed. Durham, N.C.: Duke University Press. 